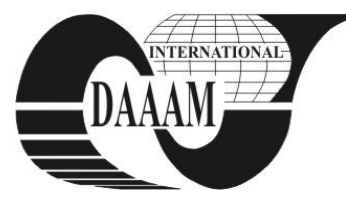

Annals of DAAAM for 2011 \& Proceedings of the 22nd International DAAAM Symposium, Volume 22, No. 1, ISSN 1726-9679 ISBN 978-3-901509-83-4, Editor B. Katalinic, Published by DAAAM International, Vienna, Austria, EU, 2011 Make Harmony between Technology and Nature, and Your Mind will Fly Free as a Bird

\title{
AN EXPRESSIVE-FUNCTIONAL ANALYSIS OF THE RELATION BETWEEN COLOR AND GENERAL FORM APPLIED IN STORAGE FURNITURE DESIGN
}

\author{
MUSCU, I[oan] \& CIONCA, M[arina] C[ristina]
}

\begin{abstract}
The paper presents a theoretical method of approaching color composition in furniture design. The method is shown in operation for a customary piece of storage furniture. It allows the designer to emphasize the expressive as well as the functional elements of the composition. The chosen storage furniture, a chest of drawers, represents the general typology of this furniture category.
\end{abstract}

Key words: tone of color, hue, chromatic harmony, general form, constructive elements

\section{INTRODUCTION}

The composition and chromatic organization in furniture design mean a multiple approach due not only to the variety of elements involved in its general expression, but also to the possibilities of analysis and understanding the composition's significant constructive, functional and expressive elements. (Beazley, 2003).

Subsequently we several aspects should be highlighted:

Materials used for furniture making are important, starting with solid wood from different species, to semi-finished elements made of wood or wood-based materials with certain specific characteristics, like veneered or variously colored and textured melamine-finished particleboards, MDF or hardboards.

Color and texture through their own characteristics and values, do not represent properties of the furniture form added at the end of the design development process, but do represent a real manifestation phenomenon of materials and natural or colored light of the environment.

Constructive elements and parts of the furniture ensemble and structure have to be taken into account.

Processing and finishing technologies of the parts, surfaces and detail forms also have a significant contribution.

Constructive and functional requirements of the entire piece of furniture as well as of those derived from the interior architectural space have to be taken into account.

Psychological and behavioral requirements of the individual in the relation with furniture are a consistent part of the approach.

Our paper presents the relation between color and the constructive elements of furniture as a method of analysis and expressive-functional design of the significant furniture form.

\section{METHOD OF APPROACH}

Steps of analysis and research:

2.1 Developing the color mixtures and obtaining the groups of derivate tones.

This is an approach of the colored substance from the constructive and expressive angle, belonging to painting and the fine arts (Constantin, 1979). For experimenting color mixture developments Corel Draw instruments were used and a graphic example for obtaining color tones was constructed.

By mixing 2/3/4 colors multiple tone groups are obtained, as seen in Fig.1, where the following examples are seen: - primary colors mixed with white, black and gray-mixed primary colors and their mixture with black- mixed secondary colors and their mixture with black (Arnheim, 1979).

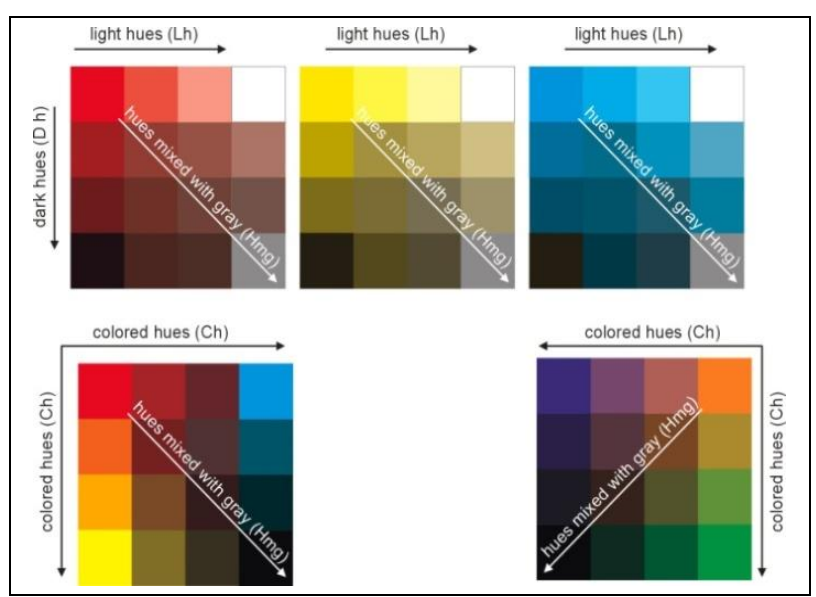

Fig.1. Tones of colors developed through pigment mixture (Itten, 1986).

2.2 Morphologic and structural analysis of a storage furniture by defining its main elements (Gall \& Muller, 1996):

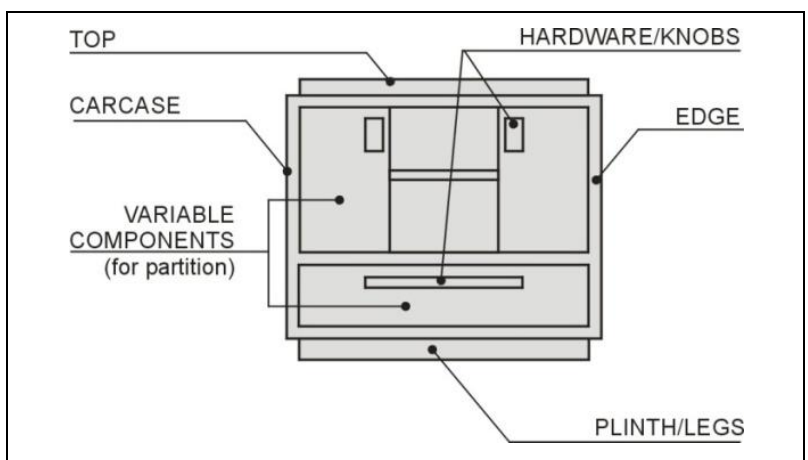

Fig. 2. Main structural elements of the form

2.3 Exercises of compositional modeling by relating the groups of chromatic tonalities with the main elements of form and structure

They require an initial idea objectively as well as subjectively defining and highlighting the furniture concept (Stem, 1989), dealing with:

a). the functional character of several important components

b). the unity and conspicuousness of the general form.

c). the contrast through chromatic varieties of the elements which compose the front of the furniture, to highlight compositional ideas related to balance, symmetry, rhythm. d). the emphasizing of preponderant horizontal or vertical directions of the components related to the general form, through color luminosity, saturation or hue contrasts. 
e). the harmonies resulted from the juxtaposition of color tones in various associations, such as: two tones in the cold, warm or neutral chromatic scale; two tones in value, saturation and tonality contrast; three tones in a scale or in contrast; other combinations.

In Fig. 3 and 4 several recommended modeling variants are presented.

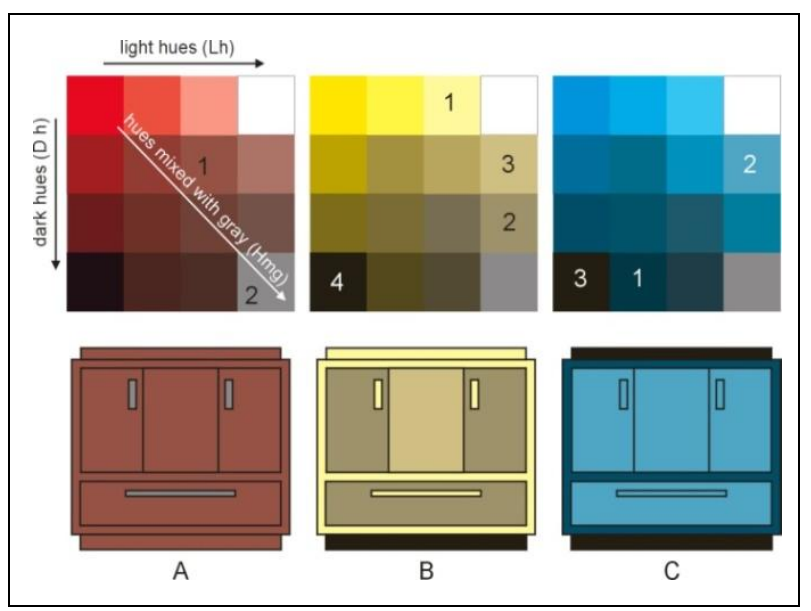

Fig. 3. Examples of chromatic modeling A - monochrome; B value contrast $(\mathrm{Lh}-\mathrm{Hmg})$; $\mathrm{C}$ - cold color scale value and saturation contrast $(\mathrm{Hmg})$

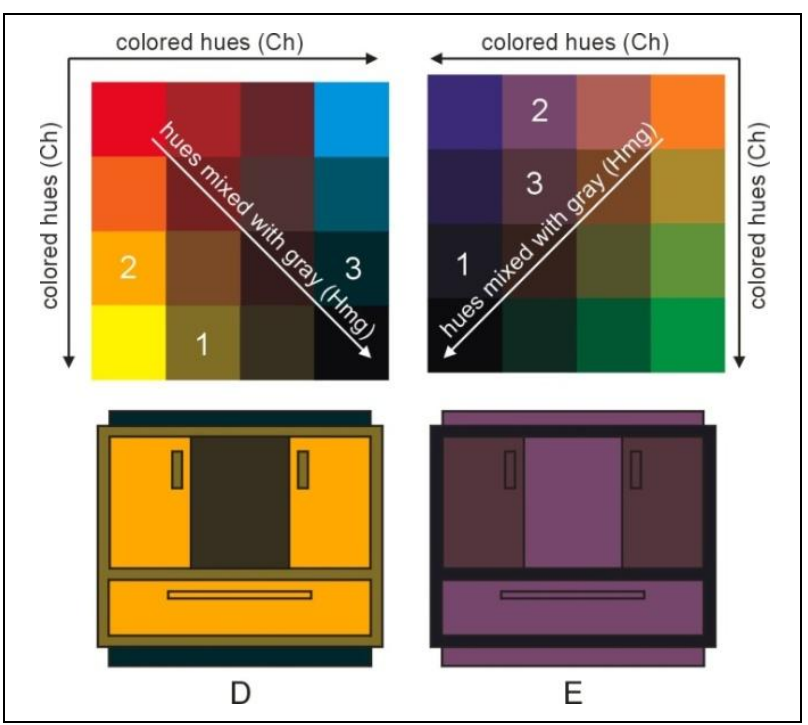

Fig. 4. Examples of chromatic modeling D - Light and dark contrast in warm color scale (Ch-Hmg); E - Depth contrast $(\mathrm{Hmg}-\mathrm{Ch})$

\subsection{Using algorithms for modeling form and color}

The versatility of the functional-expressive analysis of storage furniture is managed through the use of form and color modeling algorithms, which allow the obtaining of multiple compositional versions, presented in Fig.5.

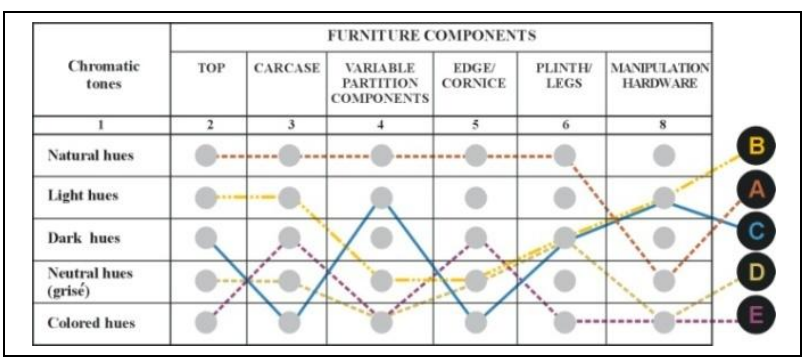

Fig. 5. Algorithms for modeling form and color
Selecting D from Fig 5, we can draw it in space, as seen in Fig.6, with the help of SolidWorks software.

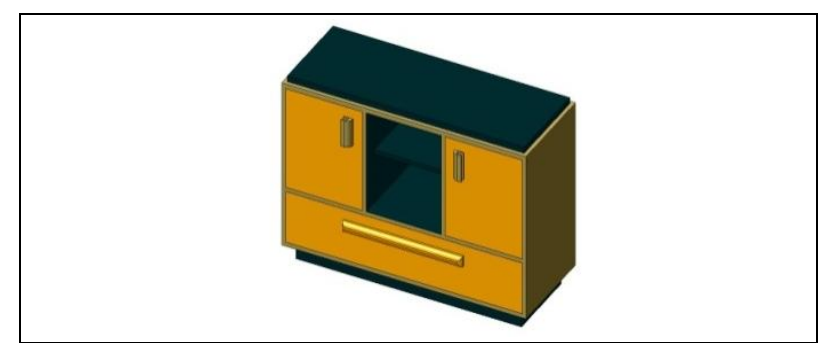

Fig. 6. 3 D representation of algorithm D

\section{CONCLUSIONS}

The composition and the chromatic organization of an object are the result of multiple approaches, with efficient and diverse results (Muscu, 2009) such as:

a) The monochromatic approach, through the variation of the luminosity and saturation of one color, succeeds in emphasizing the unity of the furniture composition.

b) The approach of chromatic harmonies as variants of applying color contrasts highlights ideas of expressive structuring and building up the furniture composition.

c) The proper chromatic composition is able to emphasize the functionality of the main elements of furniture.

d) The approach of chromatic variants as related to the existing interior space highlights the harmony and the organization of the environmental context.

e) The right choice of hues makes them able to support strongly and efficiently the concept.

f) The approach of color composition as significant expression and visual communication emphasizes the style and character of the furniture.

g) Using a reduced number of hues leads to a clear and logic expression of the whole.

h) Using an increased number of tonalities leads to a complex and decorative color effect, but might disturb the clarity of expression achieved through form and functionality.

The relation between color and form in furniture design certainly needs to be analyzed also at technological and finishing level when we think about furniture, but the main approach of the designer is to regard it as a phenomenon of perception, communication and suggestive signification which the object is able to offer (Gage, 1999).

\section{REFERENCES}

Arnheim, R.. (1979) Arta şi perceptia vizuală. O psihologie a văzului creator / Art and visual perception. A psychology of the Creative Eye, Editura Meridiane, Bucureşti

Beazley, M. (2003) The Elements of Design, Octopus Publishing Group Ltd, ISBN 1-84000-431-2, London.

Itten, J. (1986) Art de la Couleur. Edition abregée, Dessain et Tolra, ISBN 2-249-25003-0, Paris

Constantin P. (1979) Culoare Artă Ambient / Colour Art Ambient, Editura Meridiane, București

Muscu, I., (2009). Development of the form concept in the context of modernity, at the International CCSPL Workshop „Sustainable Development in Wood Industry”, Transilvania University of Brasov, Faculty of Wood Engineering, Braşov, 12-15 Oct. 2009

Stem, S. (1989). Designing Furniture, from concept to shop drawing: a practical guide, The Taunton Press, England.

Gage, J. (1999) Colours and Meaning. Art, Science and Symbolism, by Thames\&Hudson Ltd, ISBN 0-50028215-3, London

Gall, R.; Muller, U. (1996) Gestalten von Möbeln. zum Beispiel Gesellenstücke. Deutsche Verlags-Anstalt, ISBN 3-42103110-X, Stuttgart 